\title{
Predictive Psychiatric Disorders among Children and Adolescents Attending Pediatric Outpatient Department of a Tertiary Hospital in Dhaka
}

\section{Mallik CI* and Radwan RB}

Intern Physician, BIRDEM General Hospital, Dhaka, Bangladesh

\section{Research Article}

Volume 1 Issue 1

Received Date: November 02, 2017

Published Date: November 17, 2017

DOI: $10.23880 / \mathrm{mhrij}-16000109$ General Hospital, Shahabagh, Dhaka, Bangladesh, Tel: +8801515265030; E-mail: chiromallik15@gmail.com

\section{Abstract}

Introduction: Psychiatric morbidity is now a burning issue in Bangladesh and the children and adolescents of Bangladesh are suffering increasingly. Psychiatric disorders are more common in children with chronic and acute pediatric disorders. Considerable numbers of children attending in pediatric outpatient department suffer from emotional and behavioral disorders.

Objectives: The study had been designed to find out the proportion of emotional, conduct, hyperactivity and social difficulties among the children and adolescents attending pediatric outpatient department of a tertiary care hospital.

Method: This was a quantitative, cross-sectional and descriptive study and was carried out from May 2016 to June 2016 in pediatric outpatient department of a prime tertiary level hospital of Dhaka, Bangladesh. Purposive and consecutive sampling technique had been used and sample size was 100 . Both male and female children aged 4 to 18 years were included. Semi-structured questionnaire containing socio-demographic and other relevant clinical information and validated parent version of Bangla Strength and Difficulties Questionnaire (SDQ) for screening psychopathology had been applied to the consented parents or caregivers of the respondents. Version 15.0 of the SPSS had been used for statistical analysis.

Results: Mean age of the subjects was 8.17 years. Majority (80\%) of the subjects were 4 to 10 years. The male female ratio was1.3:1. Any form of predictive psychiatric disorder was 12\%. Among them 9\% was ADHD, 5\% Emotional disorder and $5 \%$ was of Conduct disorder. Proportion of any predictive psychiatric disorder was significantly higher in adolescents than in children (25\% Vs $8.8 \%$ ). All the categories of psychiatric disorders were also highly prevalent in the adolescents. Overall, $20 \%$ of the cases had peer problem and they were significantly present in the cases with predictive psychiatric disorder. 


\section{Mental Health \& Human Resilience International Journal}

Conclusion: This study supports the other findings in of predicting psychiatric disorders among the pediatric outpatients attendee population that would ultimately help in applying suitable screening procedure and importance of identification and subsequent management of psychiatric conditions.

Keywords: Psychiatric Disorders; Social Difficulties; Children and Adolescents

\section{Introduction}

Psychiatric disorders of children and adolescents are unquestionably ubiquitous and burdensome. Psychiatric disorders in childhood and adolescence concern with Emotional and Behavioral and Developmental disorders that arise in the first two decades of life [1]. Current global epidemiological data consistently reports that up to $20 \%$ of children and adolescents suffer from a disabling mental illness; and $50 \%$ of all adult mental disorders have their onset in adolescence [2]. Representative studies in the developing world generate this prevalence ranged from 1 to 49\% [3]. Child and adolescent psychiatric disorders comprised $7 \%$ in a study among attendees at walk in psychiatric clinic [4]. Bangladesh is also a developing country with the total population of about 150 million, of whom 5-14 years age group constitutes $26 \%$ of the population [5]. Childhood mental disorders among outpatient department were found $9 \%$ in the Institute of Mental Health and Research in 1990 in Bangladesh [6]. In Bangladesh, first child and adolescent mental health screening study reported that predictive prevalence of Psychiatric disorder was $17.9 \%$. Of this any Emotional disorder was $10.5 \%$, any Conduct disorder was $5.6 \%$ and any was $3.1 \%$ ADHD by using SDQ [7]. First methodologically sound epidemiological study conducted among 5 to 10 years old children in rural, urban and slum areas of Bangladesh, estimated that around 11-21\% of children and adolescents had Emotional and Behavioral disorders which were severe enough to result in substantial distress or social impairment [8]. Another large scale community survey showed psychiatric morbidity among children 5 to 17 years of age was $18 \%$ in Bangladesh [9]. Jesmin, et al. [10] conducted a study on psychiatric disorders among children and adolescents attending pediatric outpatient department of three tertiary hospitals in Dhaka city. It is reported that among the respondents, $18 \%$ were found to have any Psychiatric disorder. Behavioral disorders, Emotional disorders and Developmental disorders were found $9 \%, 15 \%$ and $0.4 \%$ respectively. ADHD was the single most frequent (5\%) psychiatric disorder.
In contrast child and adolescent mental health services are limited throughout the globe. More recent data from the WHO Mental Health Atlas (2005) found that the documented need for child and adolescent mental health services are fully met nowhere in the world [11]. The scenario is comparatively worse in developing countries including Bangladesh and massive gap exists between need and service provision.

Child psychiatric disorders often present in the context of somatic symptoms and are more common among frequent practice attendees [12]. It is also found that psychiatric disorders are more common in children with chronic and acute pediatric disorders $[13,14]$. As a result, child mental health problems are common reason for consultation in general pediatric clinics. The result of a recent study showed that $20 \%$ of children attending pediatric OPD had been suffering from some sort of Psychiatric disorders [15]. Moreover in developing countries, family may not appreciate or children may not be able to express psychological distress. They may somatize their symptoms. They and their caregivers hesitate to seek help from mental health professionals; rather they prefer pediatric setting for treatment and support.

\section{Rationale}

This study was designed to ascertain the predictive proportion of Emotional, Conduct disorder, Hyperactivity and social difficulties among children and adolescents attending at a pediatric outpatient department of a tertiary hospital. The information will help to define needs of screening and priorities of this patient group. It will also help to integrate the pediatric and child psychiatric services to deal with such patients more effectively. So far we know, the baseline data in this field related to the pediatric OPD in the place of study had yet not been explored. Thus the result of this study hopefully will help in developing and implementing service plan including identification, management of Psychiatric disorders in this population and appropriate referral 


\section{Mental Health \& Human Resilience International Journal}

system can be developed. This study will stimulate to conduct further research in this field.

\section{Objectives}

- To find out the predictive proportion of Emotional, Conduct disorder, ADHD and Social difficulties among children and adolescents attending at a pediatric outpatient department.

- To see any possible association between sociodemographic and related clinical variables and the predictive Psychiatric disorder in this population.

\section{Method}

This was a cross sectional, descriptive, quantitative survey type study with one stage design to screen out the positive cases by using screening instrument. The duration of the study was from May 2016 to June 2016. One hundred children and adolescents of either sex attending in pediatric OPD ranged from 4 to 18 years was included in the study through purposive and consecutive sampling. Those who were suffering from serious medical conditions, having impaired consciousness and not in a position to participate were excluded. The place of the study was in the pediatric OPD in Bangabandhu Sheikh Mujib Medical University Hospital, Dhaka.

Ethical clearance was obtained from the ethical clearance committee of concerned Institution. Prior permission was obtained from the respective department of the hospital. Informed verbal consent was taken before conducting the research. The research instruments were Child Data Sheet (CDS) and Strengths and Difficulties Questionnaire (SDQ). The CDS is a structured questionnaire developed by the researchers to conduct this study. It contents socio-demographic variables, family history of psychiatric illness, present medical illness. The SDQ [16-21] is a brief behavioral screening questionnaire that asks about 25 attributes, some positive and some negative. The items, which were selected on the basis of contemporary diagnostic criteria as well as factor analyses, are divided between five scales of five items each, generating scores for Emotional Symptoms, Conduct Problems, Hyperactivity, Peer Problems, and Prosocial Behaviors. All items contributing to the first four subscales are summed to generate a Total Difficulties Score. The same questionnaire can be completed in about five minutes by parents or teachers of children aged 4 to 16. There is also a self-report version [17] for those aged 11 and above. An extended version assesses the impact of any psychiatric symptoms in terms of resultant distress, social impairment or burden for others [18]. The SDQ has been shown to be of acceptable reliability and validity, performing at least as well as the lengthier and longerestablished Rutter questionnaires and Child Behavior Checklist [16-18]. The web site at www.sdqinfo.com provides more information on the SDQ plus downloadable versions of the questionnaires in many languages. The various versions of the SDQ were translated into Bangla by Mullick and Goodman [7]. The versions of the Bangla SDQ used in the study were the informants and selfreport versions including impact supplements, all being scored in the standard manner. In the present study, only Parent version of Bangla SDQ (SDQ-P) was administered on all subjects (age range 4-18 years).

Firstly, informed consent was obtained from the care givers of the respondents. Then Socio-demographic Data Sheet (SDS) was applied by one of the researchers through face to face interview. The answer was recorded accordingly. Instruction was given to the parents by one of the researchers. Then the parent version of the Bangla SDQ was distributed and field up SDQ-P was collected. Those who were not able to read, the SDQ questionnaire were read out to them and their answers were record accordingly. After that data will be cleaned and processed. Version 15.0 of the SPSS had been used for statistical analysis. Sample was divided according to age group (child and adolescent). The line of demarcation between child and adolescent was considered 11 years (i.e. child younger and adolescent older than 11 years).

\section{Results}

A total of 100 children and adolescent aged 4 to 18 years attending the pediatric outpatient department of BSMMU were taken in the study. Table 1 shows Sociodemographic characteristics of the study population and their association with predictive psychiatric disorder. It reveals that their age ranged from 4-17 years with a mean of $8.17(\mathrm{SD}=2.8)$ years. The majority of the subjects were of 4 to 10 years age (children) group which was $80 \%$ and rest were of 11 to 17 years age (adolescent) group which was $20 \%$. Boy-girl ratio was 1.3: 1 . Most of the subjects $(60 \%)$ were in the primary level education followed by preschool $29 \%$ and secondary level $11 \%$. Urban-rural distributions were $64 \%$ and $36 \%$ respectively. Majority (94\%) of the subjects was Muslim and 6\% were Hindu. Most of the subjects (32\%) were from lower income group and middle and higher income group were 58\% and $10 \%$ respectively. The socio-demographic variables were not significantly associated with the psychiatric problem. 


\section{Mental Health \& Human Resilience International Journal}

\begin{tabular}{|c|c|c|}
\hline $\begin{array}{c}\text { Socio demographic and other } \\
\text { variables }\end{array}$ & $\begin{array}{l}\text { Frequency and } \\
\text { Percentage }\end{array}$ & $\begin{array}{c}P \\
\text { value }\end{array}$ \\
\hline \multicolumn{3}{|c|}{ Age (in year) } \\
\hline - 4 to 10 years(Children) & 80 & \multirow{3}{*}{0.045} \\
\hline - 11 to 17 years(Adolescents) & \multirow{2}{*}{20} & \\
\hline Mean $=8.17( \pm 2.8)$ years & & \\
\hline \multicolumn{3}{|l|}{ Sex } \\
\hline - Male & 56 & \multirow{2}{*}{0.042} \\
\hline - Female & 44 & \\
\hline \multicolumn{3}{|c|}{ Educational level } \\
\hline - Pre-school & 29 & \multirow{3}{*}{0.03} \\
\hline - Primary level & 60 & \\
\hline - Secondary level & 11 & \\
\hline \multicolumn{3}{|l|}{ Habitat } \\
\hline • Rural & 36 & \multirow{2}{*}{0.837} \\
\hline - Urban & 64 & \\
\hline \multicolumn{3}{|c|}{ Income group } \\
\hline - Lower & 32 & \multirow{3}{*}{0.11} \\
\hline - Middle & 58 & \\
\hline - Higher & 10 & \\
\hline \multicolumn{3}{|l|}{ Religion } \\
\hline • Islam & 94 & \multirow{2}{*}{0.351} \\
\hline - Hinduism & 6 & \\
\hline
\end{tabular}

Table 1: Socio-demographic characteristics of the study population and their association with predictive psychiatric disorder $(n=100)$

The proportion of predictive Psychiatric disorders among the respondents is presented in the Figure 1. It shows that any form of predictive Psychiatric disoder was found $12 \%$ of the subjects. Figure 2 shows the proportion of any and broad categories of predictive Psychiatric disorders, and Peer problem among the respondents. It indicates that any Pychiatric disorder was 12\%, 9\% had ADHD, 5\% had Emotional disorder and the 5\% had Conduct disorder. Considering age group, any psychiatric disorder in children and adolscents were found 8.75\% and $25 \%$ respectively. The difference was higly significant. Among the children, 7.5\% had ADHD, 3.75\% had Emotional disorder and 3.75\% had Conduct disorder. In contrast, $15 \%$ had ADHD, 10\% had Emotional disorder and the $10 \%$ had Conduct disorder in adolscents. Overall, all the categories of predictive psychiatric disorder were significantly higher in adolescent group.

Peer problem was found among $20 \%$ of the cases. Of these, 6 cases was with predictive Psychaitric disorder group. In contrast, 14 cases had Peer problem without Psychiatric disorder group (13.9\%). The diference was significant $(p>0.005)$. Of the cases of Peer problem with psychiatric disorder, 4\% was with Emotionl disorder, 2\% was with Conduct disorder and the rest $3 \%$ of was with ADHD. These diferences was not significant at $5 \%$ level $(\mathrm{P}=0.295)$. Further analysis of peer problem beteen age group revels that Peer problem was found $13.75 \%$ in children and $45 \%$ in adolscents which was highly significant.

All the cases have some form of physial disorder for that they attended in the paediatric OPD. Of these, $66 \%$ was acute and the rest $34 \%$ was chronic. Table 2 shows that of the cases with predictive Psychiatric disorder, 6\% have had acute physical disorder and the rest $6 \%$ had chronic physical disorder. The differnce was not $\operatorname{significnt}(\mathrm{p}=0.212)$.

The children were came to OPD, most of them were suffering from acute illness (less then 1 year) and some them were sufferinfg from chronic illness (grater then 1 year). Among 100 children 66\% were suffering from acute illness and $34 \%$ were suffering from chronic illness. Those who probably have the Psychiatric Disorder, $6 \%$ of them were suffering from acute illness and $6 \%$ of them were suffring from chronic illness.

Throghout the period of study, reserahers observed and recorded that none of the predictive cases of psychiatric disorder was identified and refered for assessment and mangemnet.

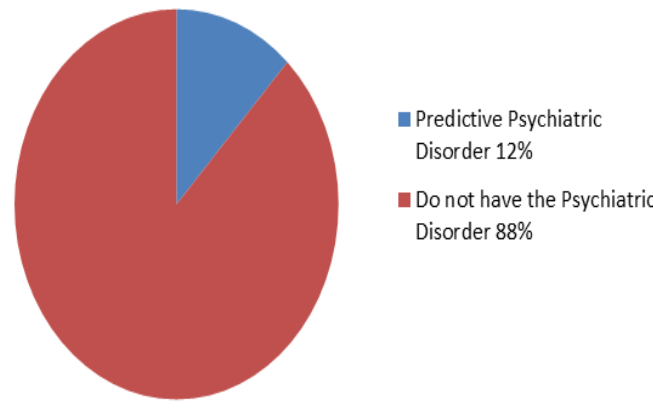

Figure 1: Proportion of predictive psychiatric disorders among the respondents $(n=100)$. 


\section{Mental Health \& Human Resilience International Journal}

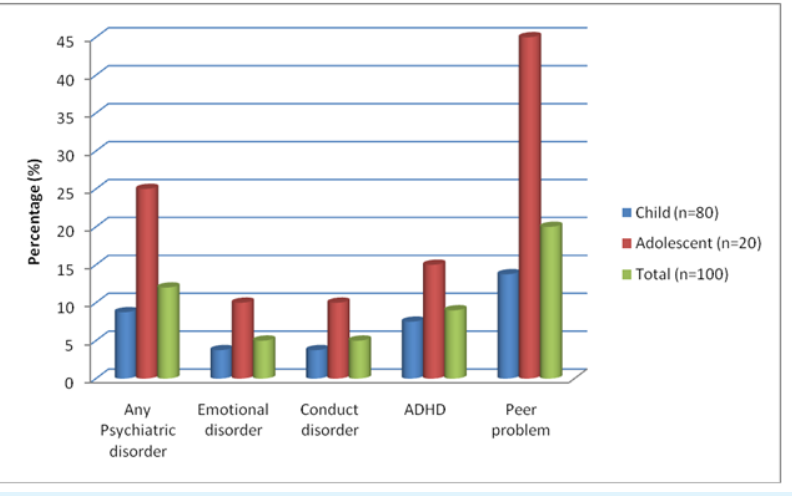

Figure 2: Proportion of categories of predictive Psychiatric disorders and peer problem among the children, adolescent and total subjects.

\begin{tabular}{|c|c|c|}
\hline $\begin{array}{c}\text { Duration of the } \\
\text { physical illness }\end{array}$ & $\begin{array}{c}\text { Predictive Psychiatric } \\
\text { disorder (\%) }\end{array}$ & $\begin{array}{c}\mathbf{P} \\
\text { value }\end{array}$ \\
\hline Acute (<1 year) & 6 & 0.212 \\
\hline Chronic (>1year) & 6 & \\
\hline
\end{tabular}

Table 2: Association of predictive Psychiatric disorder with duration of physical illness.

\section{Discussion}

Out of 100 patients of pediatric OPD, overall proportion of predictive Psychiatric disorder was $12 \%$ in this study. The result compares closely with the rates (20\%) obtained in previous studies. $[10,15,23,24]$ Similar nature of study by Jesmin et al [10] in three tertiary hospitals in Dhaka reported $18 \%$ respondents were found to have any Psychiatric disorder. However, this result is rather lower (28\%) than that of a previous UK study [15] but is found higher (1-8\% and 5\%) than Goldberg et al. studies $[25,26]$. In the present study, we used one-stage screening instrument. This inconsistent finding might have been due to different study design, instruments, and diagnostic criteria of these studies and as because of the diseases were diagnosed by the pediatrician in those studies. Proportion of predictive psychiatric disorder along with all broad categories was found significantly higher in adolescents than children (25\% Vs $8.8 \%)$. This finding is more or less consistent with the findings of several representative studies $[8,9,12,23-28]$ that prevalence is higher in adolescents.

It could be speculated that the proportion of Psychiatric disorder would be higher in a pediatric outpatient department where more sick children accumulate with physical symptoms and chronic illness. The present study finding (12\%) is almost equal with the overall prevalence of child and adolescent Psychiatric disorder $(11-21 \%$ and $18.4 \%)$ in Bangladesh [7,8]. This might be due to the selection of the study place in Dhaka city. Another reason may be the use of SDQ measures which primarily focuses on the common Emotional, Conduct and Hyperactivity disorders and does not cover less common disorders of child and adolescent.

In the study, the overall proportion of ADHD was the highest (9\%) among all predictive Psychiatric disorders. The result is highly consistent with the findings (8\%) of other studies in the Western countries [24,26]. In a similar study in Dhaka city, ADHD was the single most frequent (5\%) psychiatric disorder. On the other hand, this rate is much higher than the overall prevalence $(1 \%)$ of ADHD in Bangladesh [8]. It may be due to urban predominance of the respondents of this study who were more exposed to risk factors (like parental expectations, attitudes to and tolerance of behavior, adverse social condition, academic pressure, lead exposure and certain additives in food).

In the present study, predictive Emotional disorder was found 5\%. The study of Jesmine et al [10] in Dhaka, reported 15\% Emotional disorder. In the first community based study in Bangladesh, Mullick and Goodman [7] found $8.1 \%$ of Emotional disorder. However, the proportion of Emotional disorder more or less matched with earlier community based Western studies $[27,28]$.

In this study, we found that $5 \%$ had predictive Conduct disorder that simulates with the study of Jesmine et al with the 4\% Oppositional-Conduct disorder [10]. In the first community based study in Bangladesh, Mullick and Goodman [7] also found 8.9\% Oppositional/Conduct disorder. This can be explained by particular study place of slum area of that study. The depicted lower prevalence of present study may also due to ignorance of the family members to recognize the oppositional/Cconduct problems.

In the present study, Peer problem was found among $20 \%$ of the cases that indicates significant number of children and adolescents attended in the pediatric outpatients department had social difficulties. That could be due to impact of the existing acute and chronic physical problem combined with mental health problem. Further, half of the patients (50\%) with Psychiatric disorder have had Peer problem in comparison with $15 \%$ patients without Psychiatric disorder group. Of these Peer problem, 6 cases was with predictive Psychaitric disorder group that means half of the patents with Psychiatric disorder have had Peer problem. In contrast, 16 cases had 


\section{Mental Health \& Human Resilience International Journal}

Peer problem without Psychiatric disorder group (15.9\%) that is highly significant. Further, it might be the fact that some of the cases with peer problem in the without Psychiatric disorder group had developmental problems including Autism spectrum disorder as these problems are usually not be screened with the SDQ. These area need to be explored for better understanding.

As observed in this study, all the cases with predictive Psychiatric disorder had either acute or chronic physical illness. It is evident that Psychiatric disorders are more common in children with chronic and acute pediatric disorders [13.14]. Higher findings but insignificant correlation between psychiatric disorder and physical illness in the present study might be due to small sample size and perhaps the psychiatric disorder of severe nature associated with physical illness do not attend in pediatric outpatients clinics.

Throughout the period of conducting this study, researchers carefully observed and recorded that none of the cases were identified as having possible Psychiatric disorder and thereby not referred to psychiatry outpatient department for psychiatric consultation. This is very much indicative of the lack of awareness at all level of the concerned professionals. There exists service gap in term of identification and referral and managing the cases.

The study was conducted in tertiary hospitals of Dhaka city with relatively small sample size. The study population is not representing the whole child and adolescent population. We used only parent version for screening measure due to lack of feasibility in this type of facility setup where people comes almost all corners of the country. Moreover, we did not perform diagnostic assessment using structured measures of child psychopathology. These limit generalization of the results. However, the results have strong predictive value as we used culturally adopted and validated screening tool.

\section{Conclusion}

This study explores and supports the existence of wide magnitude of the problems of Psychiatric disorders in pediatric settings in Bangladesh. ADHD is of high preponderance among them. Psychiatric disorders are frequent in pediatric outpatient department as they are associated with enhanced reporting of physical symptoms. Probably, this will be higher in larger sample. Thus it echo the need for effective hospital based pediatric-psychiatric liaison service as well as similar combined approach at root level. Further broad based and in-depth research need to be carried out to address the issue.

\section{References}

1. Murray RM, Kendler KS, Mcguffin P, Wessely S, Castle DJ (2008) Essential Psychiatry. ${ }^{\text {th }}$ (edn), Cambridge: Cambridge University Press, pp: 97.

2. Belfer ML (2008) Child and adolescent mental disorders: the magnitude of the problem across the globe. Journal of Child Psychology and Psychiatry 49(3): 226-236.

3. Hackett R, Hackett L (1999) Child psychiatry across cultures. International Review of Psychiatry 11(2-3): 225-235.

4. Younis MS, Al-Noaimi AS, Zaidan ZA, Al-Rubayie AF, Al-Farsi Y, et al. (2013) Clinical and Demographic Profile of Attendees at Baghdad's Walk-in Psychiatric Clinic. Oman Medical Journal 28(5): 365-370.

5. BBS (2010) Bangladesh Bureau of Statistics. Statistical Pocketbook of Bangladesh, Dhaka.

6. Mullick MSI, Khanom M, Islam H (1995) Psychiatric morbidity of outpatient children in institute of mental health and research. Bangladesh Journal of Psychiatry 7(1): 4-8.

7. Mullick M, Goodman R (2001) Questionnaire screening for mental health problems in Bangladeshi children: a preliminary study. Social Psychiatry and Psychiatric Epidemiology 36(2): 94-99.

8. Mullick MSI and Goodman R (2005) The prevalence of psychiatric disorders among 5-10 year olds in rural, urban and slum areas in Bangladesh. An exploratory study. Social Psychiatry and Psychiatric Epidemiology 40(8): 663-671.

9. Rabbani MG, Alam MF, Ahmed HU, Sarkar M, Islam MS, et al. (2009) Prevalence of mental disorders, mental retardation, epilepsy and substance abuse in children. Bangladesh Journal of Psychiatry 23: 11-52.

10. Jesmin A, Mullick MSI, Rahman KMZR, Muntasir MM (2016) Psychiatric disorders in children and adolescents attending pediatric outpatient department of tertiary hospitals. Oman Medical Journal 31(4): 253-257. 


\section{Mental Health \& Human Resilience International Journal}

11. WHO (2005) Atlas: child and adolescent mental health resources. global concerns: implications for the future. World Health Organization, Geneva, p: 16.

12. Jezzard RG (1995) Child and adolescent psychiatric disorders in general practice. Advances in Psychiatric Treatment 1(7): 184-191.

13. Gledhill J, Rangel L, Garralda ME (2000) Surviving chronic physical illness: Psychosocial outcome in adult life. Archives of Disorder in Childhood 83(2): 104-110.

14. Judge D, Nadel S, Vergnaud S, Garralda ME (2002) Psychiatric adjustment following meningococcal disease treated on a PICU. Intensive Care Medicine 28(5): 648-650.

15. Glazebrook C, Hollis C, Heussler H, Goodman R, Coates L (2003) Detecting emotional and behavioural problems in paediatric clinics. Child Care Health and Development 29(2): 141-149.

16. Goodman R (1997) The Strengths and Difficulties Questionnaire: A research note. Journal of Child Psychology and Psychiatry 38(5): 581-586.

17. Goodman R, Meltzer H, Bailey V (1998) The Strengths and Difficulties Questionnaire: a pilot study on the validity of the self-report version. European Child \& Adolescent Psychiatry 7(3): 125-130.

18. Goodman R (1999) The extended version of the Strengths and Difficulties Questionnaire as a guide to child psychiatric caseness and consequent burden. Journal of Child Psychology and Psychiatry 40(5): 791799.

19. Goodman R, Ford T, Simmons H, Gatward R, Meltzer H (2000) Using the Strengths and Difficulties Questionnaire (SDQ) to screen for child psychiatric disorder in a community sample. British Journal of Psychiatry 177(6): 534-539.

20. Goodman R, Renfrew D, Mullick M (2000b) Predicting type of psychiatric disorder from Strengths and
Difficulties Questionnaire (SDQ) scores in child mental health clinics in London and Dhaka, European Child and Adolescent Psychiatry 9(2): 129-134.

21. Goodman R, Scott S (1999) Comparing the Strengths and Difficulties Questionnaire and the Child Behavior Checklist: Is small beautiful?. Journal of Abnormal Child Psychology 27(1): 17-24.

22. Briggs-Gowan MJ, Horwitz SM, Schwab-Stone ME, Leventhal JM, Leaf PJ (2000) Mental health in pediatric settings: distribution of disorders and factors related to service use. J Am Acad Child Adolesc Psychiatry 39(7): 841-849.

23. Costello EJ, Costello AJ, Edelbrock C, Burns BJ, Dulcan MK, et al. (1988) Psychiatric disorders in pediatric primary care. Prevalence and risk factors. Arch Gen Psychiatry 45(12): 1107-1116.

24. Garralda ME, Bailey D (1989) Psychiatric disorders in general pediatric referrals. Archives of Disorder in Childhood 64(12): 1727-1733.

25. Goldberg ID, Regier DA, Mclnerny TK, Pless IB, Roghmann KJ (1979) The role of the pediatrician in the delivery of mental health services to children. Pediatrics 63(6): 898-909.

26. Goldberg ID, Roghmann KJ, Mclnerny TK, Burke JDJr (1984) Mental health problems among children seen in pediatric practice: prevalence and management. Pediatrics 73(3): 278-293.

27. Ford T, Goodman R, Meltzer H (2003) The British Child and Adolescent Mental Health Survey 1999: The prevalence of DSM-IV disorders. Journal of American Academy of Child \& Adolescent Psychiatry 42(10): 1203-1211.

28. Meltzer H, Gatward R, Goodman R, Ford T (2000) Mental health of children and adolescents in Great Britain. The Stationery Office, London. 